Stéphane Pascau, Écrire et s'enfuir, dans l'ombre des Lumières. Henri-Joseph Dulaurens (1719-1793)

\title{
Catriona Seth
}

\section{(2) OpenEdition \\ 1 Journals}

\section{Édition électronique}

URL : https://journals.openedition.org/ahrf/11909

DOI : 10.4000/ahrf.11909

ISSN : 1952-403X

Éditeur :

Armand Colin, Société des études robespierristes

\section{Édition imprimée}

Date de publication : 1 décembre 2010

Pagination : 190

ISBN : 978-2-200-92634-2

ISSN : 0003-4436

\section{Référence électronique}

Catriona Seth, «Stéphane Pascau, Écrire et s'enfuir, dans l'ombre des Lumières. Henri-Joseph Dulaurens (1719-1793) », Annales historiques de la Révolution française [En ligne], 362 I octobredécembre 2010, mis en ligne le 25 mars 2011, consulté le 24 avril 2022. URL : http:// journals.openedition.org/ahrf/11909; DOI : https://doi.org/10.4000/ahrf.11909

Ce document a été généré automatiquement le 24 avril 2022.

Tous droits réservés 


\title{
Stéphane Pascau, Écrire et s'enfuir, dans l'ombre des Lumières. Henri- Joseph Dulaurens (1719-1793)
}

\author{
Catriona Seth
}

\section{RÉFÉRENCE}

Stéphane Pascau, Écrire et s'enfuir, dans l'ombre des Lumières. Henri-Joseph Dulaurens (1719-1793), Paris, Éditions les points sur les i, 2009, 328 p., ISBN 978-2-359-30002-4, $25 €$

1 La série dans laquelle s'inscrit cet ouvrage, intitulée "Collection des gueux littéraires ", dit assez le parti-pris de cet essai biographique très documenté. La collection se donne pour sous-titre "Histoire de la littérature marginale ", ce qui convient à de nombreux égards pour décrire l'œuvre de Dulaurens. En effet, cet auteur est à plus d'un titre un marginal des lettres, c'est aussi et surtout quelqu'un à qui il arrive d'écrire en marge des textes de contemporains. Son livre le plus célèbre, un véritable best-seller du second rang au XVIII ${ }^{\mathrm{e}}$ siècle, Le Compère Mathieu ou Les Bigarrures de l'esprit humain, qui a fait l'objet d'une récente réédition, s'inscrit, à sa façon, en marge de Candide. Dulaurens paraît souvent être comme le reflet moqueur des grands de son temps, une sorte de caricature ironique ou un bouffon grinçant, dénonçant les dérives des Lumières.

L'auteur de l'étude s'est imposé comme un spécialiste du parcours chaotique de Dulaurens grâce à une thèse, à plusieurs articles et à un premier livre (Henri-Joseph Dulaurens (1719-1793), réhabilitation d'une ceuvre, Paris, Champion, 2006). Le présent ouvrage est construit en quatre parties de longueurs inégales : Préambule stylistique La fuite géographique - La fuite philosophique - Un exutoire : l'écriture. Ce refus d'un tracé linéaire dans un travail proche de la tradition de "L'homme et l'œuvre » rend particulièrement bien compte d'une existence errante due à un goût du voyage mâtiné d'exils imposés. La chronologie incluse en fin de volume permet de situer à tout 
moment les œuvres dont il est question dans un déroulement biographique clairement articulé dont les principaux épisodes sont par ailleurs narrés en cours de route. Plusieurs thèmes centraux sont mis en évidence par Stéphane Pascau, comme la haine des Jésuites qui informe plusieurs pans de l'œuvre de Dulaurens ou encore la maladie et la médecine - signalons au passage qu'il faudrait distinguer vérole et petite vérole (p. 260) - là encore présents à divers niveaux dans les écrits de cet abbé pas très orthodoxe.

3 L'essai est accompagné d'annexes fort utiles. La bibliographie très documentée sera précieuse pour toute personne qui s'intéresse non seulement à Dulaurens, mais aussi aux aventuriers des lettres et aux Rousseau du ruisseau. Les quelques illustrations, en particulier un cahier iconographique central, constituent également des apports appréciables. La dernière planche du cahier, tirée d'une édition de 1793 du Compère Mathieu, publiée supposément "à Malthe, aux dépens du Grand Maître ", ne manque de faire songer à Sade, l'un des auteurs dont le succès est en partie responsable de l'éclipse de la notoriété de Dulaurens. L'érudition de S. Pascau est impressionnante. Le présent ouvrage, avec les articles pionniers d'Annie Rivara, plusieurs rééditions, ainsi qu'une récente monographie de Michèle Bokobza-Kahan sur Dulaurens (Dulaurens et son cuvre. Un auteur marginal au XVIII' siècle, Paris, Champion, 2009), aident à faire sortir de l'ombre une figure intéressante. De telles études sur des personnages mineurs ou marginaux sont éclairants pour qui s'intéresse à la période : elles permettent de mieux cerner et comprendre les complexités de la république des lettres. 